\title{
ANIMAL SCIENCE \\ Effects of fish oil on the production performances, polyunsaturated fatty acids and cholesterol levels of yolk in hens
}

\author{
Ahmed Ali Saleh* \\ Department of Poultry Production, Faculty of Agriculture, Kafrelsheikh University, 333516 Kafr El-Sheikh, Egypt
}

\begin{abstract}
This study was conducted to show that dietary supplementation of fish oil, effects growth performance, egg quality and decreases yolk cholesterol in laying hens. One hundred twenty Bovans white hens at their 23rd week of age were housed individually in cages in an open sided house. The birds were kept under a $16 \mathrm{hr}$ light: $8 \mathrm{hr}$ dark lighting schedule (lights on between 06:00 and 22:00 hr). Birds were randomly divided into five dietary treatments and 3 replicates in each ( 8 birds per replicate); the first treatment group was control and given $0 \%$ fish oil $+5 \%$ vegetable oil, the second treatment given $1.25 \%$ fish oil $+3.75 \%$ vegetable oil, the third treatment given $2.5 \%$ fish oil $+2.5 \%$ vegetable oil, the fourth treatment given $3.75 \%$ fish oil $+1.25 \%$ vegetable oil and the fifth treatment given 5\% fish oil $+0 \%$ vegetable oil. The birds were raised for 12 weeks from 23 weeks of age to evaluate the effect on growth, egg quality, yolk cholesterol and linoleic and linolenic fatty acids content in yolk. Body weight gain was increased significantly $(\mathrm{P} \leq 0.05)$ by $9.2 \%$ in birds fed diets content $3.5 \%$ fish oil, as compared with those fed on control diet and feed intake was decreased significantly $(\mathrm{P} \leq 0.05)$ by $26.4 \%$ in birds fed diets content $5 \%$ fish oil, as compared with those fed on control diet. Also, egg weight was decreased significantly. Due to fish oil egg quality were improved. Interestingly, yolk cholesterol was decreased significantly $(\mathrm{P} \leq 0.05)$ by $14.5 \%$ in birds fed diets content $3.5 \%$ fish oil, as compared with those fed on control diet. Furthermore, it was observed significantly increase $(\mathrm{P} \leq 0.05)$ in linolenic fatty acid content in yolk by $30.5 \%$ in birds fed diets content $3.5 \%$ fish oil, as compared with those fed on control diet. In conclusion, feeding fish oil deceased feed intake, egg weight and egg production on the other hand, increased unsaturated fatty acids and cholesterol content in yolk in laying hens.
\end{abstract}

Key words: Omega-3 fatty acids, Hens, Egg quality, Cholesterol, Performance

\section{Introduction}

Eggs are considered as an important part of human feeding since the dawn of recorded history. Good taste and numerous applications in preparing a wide variety of foods lead to increase the egg consumption in the world year by year. The egg functional proteins have been recognized as one of the highest quality proteins in digestibility as well as amino acid composition. Hen eggs have been evaluated as a source of essential fatty acids, and several vitamins and minerals thus, daily intake of hen eggs supply nearly the amount recommended of our daily allowance of such materials. These advantages qualify hen eggs to be one of the

Received 21 August 2012; Revised 20 December 2012; Accepted 01 January 2013; Published Online 01 June 2013

*Corresponding Author

Ahmed Ali Saleh

Department of Poultry Production, Faculty of Agriculture, Kafrelsheikh University, 333516 Kafr El-Sheikh, Egypt

Email: a_saleh2006@yahoo.com promising functional foods in the coming decades according to their relation to the human health. Functional foods may be defined as foods or food ingredients that may enhance health through their provision of a physiological benefit beyond traditional nutrients. Examples of functional foods include foods that contain specific minerals, vitamins, dietary fiber, foods with added biologically active fatty acids or substances such as phytochemicals or other antioxidants and probiotics. Being a functional food has been revealed new trends in egg production like designer eggs and specialty eggs (Eid, 2005). Omega-3polyunsaturated fatty acids (n-3PUFA) play an important role in human nutrition since they help to reduce the incidence of such life-style diseases as coronary artery diseases, hypertension and diabetes, as well as certain inflammatory diseases as arthritis and dermatitis (Simopoulos, 2000). These diseases are an increasing problem in countries of the Middle East and North Africa, due to the dominance of animal fats and partially 
hydrogenated vegetable oils in these countries. Enrichment of n-3PUFA in eggs of laying hens is a successful strategy to ensure an adequate supply of n-3PUFA for the greater population. Production of such eggs can be realized by adding common sources of n-3PUFA (i.e., fish oil, marine algae, or flaxseed) to the layer diet (Baucells et al., 2000). The inclusion of n-3PUFA into yolk lipids is feasible and could be achieved by feeding diets rich in n-3PUFA to the laying hens. Fish oils are common feed ingredients used to increase yolk n-3 PUFA in layers (Gonzalez Esquerra and Leeson, 2000). The optimal concentration of n-3PUFA in a layer diet must be optimized experimentally for each production (Pappas et al., 2005). Several studies indicated that dietary supplemented with fish oil had only minor effects on layer performance. Egg production did not affected by including fish oil in commercial layer diets (Schreiner et al., 2004). However others said that egg weight was reduced due to fish oil supplementation (Van Elswyk et al., 1995). Contrarily, Schreiner et al. (2004) indicated that fish oil supplementation had no significantly effect on egg weight and feed intake. Therefore, the objectives of the current study are to produce omega-3 enriched eggs using different quantities of fish oil $(0,1.25,2.5,3.5$ or $5 \%)$ to determine the effects of n-3 PUFA on hens' performance, egg quality characteristics, and egg yolk cholesterol, and quantify alpha-linolenic n-3PUFA, and linoleic n-6PUFA in eggs' yolk from laying hens.

\section{Materials and Methods}

The experiment was carried out at the Poultry Research Farm, Department of Poultry Production, Faculty of Agriculture, Kafr El- Sheikh University, Egypt.

\section{Birds and management}

One hundred twenty Bovans white hens at their 23rd week of age were housed individually in cages in an open sided house. The birds were kept under a $16 \mathrm{hr}$ light: $8 \mathrm{hr}$ dark lighting schedule (lights on between 06:00 and 22:00 hr). Birds were randomly divided into five dietary treatments and 3 replicates in each ( 8 birds per replicate); the first treatment group was given $5 \%$ fish oil, the second treatment given $3.5 \%$ fish oil $+1.5 \%$ vegetable oil, the third treatment given $2.5 \%$ fish oil $+2.5 \%$ vegetable oil, the fourth treatment given $1.25 \%$ fish oil $+3.75 \%$ vegetable oil and the fifth treatment given 5\% vegetable oil. The ingredient composition and calculated analysis of the experimental diets shows in Table 1. The calculated values of the diets were based on metabolizable energy (ME) values of feed ingredients as listed by national research council (NRC, 2003).

Table 1. Composition of experimental diets.

\begin{tabular}{|c|c|c|c|c|c|}
\hline \multirow{2}{*}{ Ingredient } & \multicolumn{5}{|l|}{$\%$} \\
\hline & Control & $\mathrm{T} 1$ & $\mathrm{~T} 2$ & T3 & $\mathrm{T} 4$ \\
\hline Corn & 58.67 & 58.67 & 58.67 & 58.67 & 58.67 \\
\hline Soybean & 18 & 18 & 18 & 18 & 18 \\
\hline Layer concentrate* & 10 & 10 & 10 & 10 & 10 \\
\hline Limestone & 7.5 & 7.5 & 7.5 & 7.5 & 7.5 \\
\hline Dicalcium phosphate & 0.5 & 0.5 & 0.5 & 0.5 & 0.5 \\
\hline $\mathrm{NaCl}$ & 0.3 & 0.3 & 0.3 & 0.3 & 0.3 \\
\hline DL-Methionine & 0.03 & 0.03 & 0.03 & 0.03 & 0.03 \\
\hline Fish oil & 0 & 1.25 & 2.5 & 3.5 & 5 \\
\hline Vegetable oil & 5 & 3.75 & 2.5 & 1.5 & 0 \\
\hline \multicolumn{6}{|l|}{ Fatty acids analysis } \\
\hline $\mathrm{N}-3 \mathrm{FA}^{\mathrm{I}}$ & 1.01 & 1.35 & 2.63 & 3.76 & 5.52 \\
\hline $\mathrm{SFA}^{2}$ & 32.02 & 30.67 & 29.36 & 27.1 & 21.01 \\
\hline $\mathrm{USFA}^{3}$ & 67.98 & 69.33 & 70.64 & 72.9 & 78.98 \\
\hline \multicolumn{6}{|l|}{ Calculated analysis ${ }^{4}$} \\
\hline $\mathrm{CP} \%$ & 18 & 18 & 18 & 18 & 18 \\
\hline $\mathrm{ME}, \mathrm{kcal} / \mathrm{kg}$ & 2840 & 2840 & 2840 & 2840 & 2840 \\
\hline Calcium, $\%$ & 3.8 & 3.8 & 3.8 & 3.8 & 3.8 \\
\hline Available phosphorus,\% & 0.44 & 0.44 & 0.44 & 0.44 & 0.44 \\
\hline
\end{tabular}




\section{Sampling}

Egg production was recorded daily; feed consumption, body weight and egg weight were recorded weekly, fatty acids analysis, cholesterol in egg and egg quality was determined every 3 weeks.

\section{Live body weight}

The birds were weighed at the start of the experiment, and then they were weighed weekly.

\section{Percentage of egg production}

Eggs were collected and recorded daily. Egg production was expressed as hen-day production and calculated using the following equation:

$$
\begin{aligned}
& \text { Egg production= } \text { Number of eggs produced } \\
& \text { Number of live hens housed }
\end{aligned}
$$

\section{Feed consumption}

The diets were provided regularly at $8 \mathrm{Am}$ daily with enough per weighted ration per each hen. Feed intake per each hen was calculated by figuring out the difference between the weights of offered feed and the remained part at the end of week.

\section{Egg weight}

Eggs were collected and evaluated daily.

\section{Egg quality analysis \\ Egg shape index}

The two axis of the egg was measured using the Vernier calipers then calculating egg-shape index as:

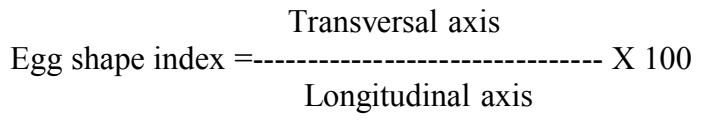

\section{Albumen and yolk height}

The height of thick albumen and yolk were measured with tripod micrometer (in $\mathrm{mm}$ ).

\section{Albumen index and yolk index}

Longitudinal and diagonal width of albumen and yolk widths were taken. The albumen and yolk indices were then calculated as follows:

$$
\begin{aligned}
& \text { Albumen height } \\
& \text { Albumen width }
\end{aligned}
$$

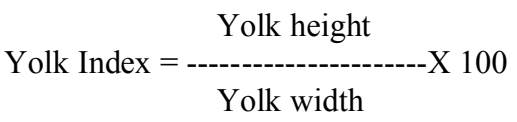

\section{Shell thickness}

Shell were rinsed with tap water; the shell membranes manually removed and then dried at $100^{\circ} \mathrm{C}$ for $2 \mathrm{hr}$. Shell thickness was measured to the nearest micron by using a metric micrometer equipped with a spherical tip. Estimates were done at the middle part of each egg.

\begin{abstract}
Absolute and relative weight of egg components
Egg was broken and yolk was carefully separated as perfectly as possible by hand and weighed to the nearest gram. The shell was carefully washed to remove the albumen and dried at $100^{\circ} \mathrm{C}$ for two hours and weighed before cooling (Garlich et al., 1975). Shell weight percentage including the membranes was calculated (shell weight $\mathrm{x} 100 /$ egg weight). Albumen weight was determined by subtracting yolk weight and dry shell weight from the initial whole egg weight. Relative weight of each egg component to the intact egg weight was then calculated.
\end{abstract}

\section{Albumen condition (Haugh Units)}

This was measured according to the next formula:

$\begin{aligned} \text { Hugh Units } & =100 \mathrm{x} \log (\mathrm{H}-1.7 \mathrm{~W} 0.37+7.57) .(1.7,7.57 \\ & \text { and } 0.37 \text { are constants }) .\end{aligned}$

Where:

$\mathrm{H}=$ the height of thick albumen.

$\mathrm{W}=$ the egg weight.

\section{Biochemical analysis}

Five samples per replicate used for cholesterol and fatty acids analysis. Egg yolk cholesterol was determined by method of Richmond (1973), by using "Cholesterol CHOD-PAP Kits" which produced by Human, Germany. Fatty acids were analyzed by using the method described by Radwan (1978) Lipids were extracted from egg yolk by a mixture of chloroform methanol (2:1) at the ratio of (1:5) in separator funnel and shake carefully for one hour. Let the extract to be separated, the organic layer was taken, then passed through glass funnel contained anhydrous sodium sulfate and finally evaporated to near dryness by a stream of nitrogen Preparation of fatty acids methyl esters from lipids of sample was performed according to the procedure of Radwan (1978). Sample of total lipids $(50 \mathrm{mg}$ ) was transferred into screw-cap vial, $2 \mathrm{ml}$ benzene and $10 \mathrm{ml} 1 \% \mathrm{H}_{2} \mathrm{SO}_{4}$ in absolute methanol was added. The vial was covered under a stream of nitrogen before heating in an oven at $90^{\circ} \mathrm{C}$ for 90 min. Ten $\mathrm{ml}$ of distilled water were added to the cooled vial and the methyl esters in each vial were extracted. Ether extracts were combined and concentrated to its minimum volume by using a stream of nitrogen. Analysis of fatty acids was carried out by gas liquid chromatography (GLC) using Shimadzu gas chromatograph GC-4 CM 
(PFE) equipped with flame ionization detector (FID) under the following conditions. An analytical glass column ( $3 \mathrm{~m} \mathrm{X} \mathrm{3mm} \mathrm{I'd)} \mathrm{packed} \mathrm{with} 5 \%$ (DEGS) diethyl glycol succinct on 80/100 Chrome Operating temperatures (C) for column $180{ }^{\circ} \mathrm{C}$ isothermal, injector and detector $270^{\circ} \mathrm{C}$, gas flow rates $(\mathrm{ml} / \mathrm{min})$ nitrogen 30 , hydrogen 1 , air 0.5 , chart speed $0.5 \mathrm{~mm} / \mathrm{min}$. A standard mixture of methyl esters was analyzed under identical conditions prior to running the samples. The retention times of the unknown sample of methyl esters were compared with those of the standard. The concentration of methyl esters were calculated by the triangulation method (Brandt, 1968).

\section{DT}

\section{Statistical analysis}

The differences among treatment groups and the control group were analyzed by General Liner model using SPSS Statistics 17.0 (Statistical Packages for the Social Sciences, released 23 August 2008). The significant differences among means of treatments were compared by Tukey test. $\mathrm{P} \leq 0.05$ was set as limit of significance.

\section{Results}

Effects of fish oil on final body weight, feed intake, egg weight and egg production are summarized in Table 2. Fish oil increased the final body weight significantly $(\mathrm{P}<0.05)$ when the level was $3.5 \%$ and $2.5 \%$, respectively, but not in other treatment groups. Feed intake decreased significantly in all experimental groups. Egg weight was decreased $(\mathrm{P}<0.05) \quad$ in the treatment groups except $1.25 \%$ fish oil. Egg production was decreased by feeding fish oil.

Effects of fish oil on egg quality characteristic are summarized in Table 3. Egg index, albumen height, albumen index, yolk index, haugh units, albumen $\%$, and yolk \% were not influenced by feeding fish oil. Shell thickness of eggs from hens fed diets $50 \mathrm{~g}$ fish oil $/ \mathrm{kg}$ diet was not significantly different from those of the control. By feeding fish oil yolk yellow color was increased significantly.

Effects of fish oil on yolk cholesterol, omega-3 and omega- 6 fatty acids are shown in Fig.1A,B and C. Yolk cholesterol was decreased significantly in all experimental groups except $1.25 \%$ fish oil. Omega-3 fatty acids content in yolk was increased significantly by feeding fish oil while, omega- 6 was decreased.

Table. 2. Effect of dietary fish oil on body weight, feed intake, egg weight and egg production.

\begin{tabular}{llllll}
\hline & \multicolumn{5}{l}{ Fish oil \% } \\
\cline { 2 - 5 } & Control & 1.25 & 2.5 & 3.5 & 5 \\
\hline Final Body weight, g & $1321 \pm 39^{\mathrm{b}}$ & $1369 \pm 41^{\mathrm{b}}$ & $1425 \pm 63^{\mathrm{a}}$ & $1455 \pm 66^{\mathrm{a}}$ & $1398 \pm 64^{\mathrm{ab}}$ \\
Feed intake, g/d & $121 \pm 9^{\mathrm{a}}$ & $99 \pm 7^{\mathrm{b}}$ & $98 \pm 5^{\mathrm{b}}$ & $91 \pm 4^{\mathrm{b}}$ & $89 \pm 4^{\mathrm{b}}$ \\
Egg weight, g & $55 \pm 2.1^{\mathrm{a}}$ & $54.2 \pm 2^{\mathrm{a}}$ & $50.9 \pm 1.8^{\mathrm{b}}$ & $51.0 \pm 1.8^{\mathrm{b}}$ & $50.2 \pm 2^{\mathrm{b}}$ \\
Egg production, \% & $89.3 \pm 3^{\mathrm{a}}$ & $86 \pm 3^{\mathrm{b}}$ & $85.9 \pm 4^{\mathrm{b}}$ & $85.2 \pm 5^{\mathrm{b}}$ & $88 \pm 3^{\mathrm{ab}}$ \\
Values are expressed as means \pm standard error. $;$ a-b Means with different superscripts differ from each other significantly & &
\end{tabular}

Table 3. Effect of feeding different levels of fish oil on egg quality over all mean of experimental.

\begin{tabular}{|c|c|c|c|c|c|}
\hline \multirow{2}{*}{ Characteristic } & \multicolumn{5}{|l|}{ Fish oil \% } \\
\hline & Control & 1.25 & 2.5 & 3.5 & 5 \\
\hline Egg index & $77.84 \pm 14.11$ & $75.91 \pm 2.34$ & $73.93 \pm 2.34$ & $72.97 \pm 2.23$ & $71.2 \pm 2.26$ \\
\hline Shell (\%) & $9.54 \pm 0.52^{b}$ & $9.64 \pm 0.67^{\mathrm{ab}}$ & $9.71 \pm 0.90^{\mathrm{ab}}$ & $10.04 \pm 0.58^{\mathrm{a}}$ & $9.99 \pm 0.62^{\mathrm{a}}$ \\
\hline Shell thickness (mm) & $0.389^{\mathrm{b}} \pm 0.03$ & $0.401^{\mathrm{b}} \pm 0.031$ & $0.409^{\mathrm{b}} \pm 0.022$ & $0.420^{\mathrm{a}} \pm 0.029$ & $0.418^{\mathrm{ab}} \pm 0.025$ \\
\hline Albumen height (mm) & $9.29 \pm 1.5$ & $9.39 \pm 1.59$ & $9.69 \pm 1.06$ & $9.68 \pm 1.06$ & $9.6 \pm 1.26$ \\
\hline Albumen index $(\%)$ & $13.76 \pm 1.96$ & $13.7 \pm 2.53$ & $14.36 \pm 1.49$ & $14.34 \pm 1.4$ & $13.94 \pm 1.99$ \\
\hline Albumen (\%) & $65.5 \pm 2.71$ & $65.33 \pm 2.65$ & $66.17 \pm 1.8$ & $66.9 \pm 2.18$ & $66.19 \pm 1.96$ \\
\hline Yolk height (mm) & $19.02 \pm 2.56^{\mathrm{a}}$ & $18.36 \pm 1.09^{\mathrm{a}}$ & $18.53 \pm 1.15^{\mathrm{a}}$ & $18.98 \pm 0.94^{\mathrm{a}}$ & $16.74 \pm 0.89^{b}$ \\
\hline Yolk color & $8.12^{\mathrm{b}} \pm 0.81$ & $8.91^{\mathrm{a}} \pm 0.77$ & $8.87^{\mathrm{a}} \pm 0.74$ & $8.87^{\mathrm{a}} \pm 0.61$ & $9.16 \pm 0.56^{\mathrm{a}}$ \\
\hline Yolk index (\%) & $45.43 \pm 8.88$ & $48.21 \pm 4.99$ & $48.72 \pm 5.11$ & $48.78 \pm 4.26$ & $48.71 \pm 3.94$ \\
\hline Yolk (\%) & $23.41 \pm 2.81$ & $23.74 \pm 2.7$ & $24.11 \pm 1.56$ & $24.12 \pm 2.14$ & $25.16 \pm 1.96$ \\
\hline Haugh Units & $96.66 \pm 7.88$ & $97.45 \pm 6.96$ & $98.54 \pm 4.66$ & $98.2 \pm 4.45$ & $97.66 \pm 6.14$ \\
\hline
\end{tabular}




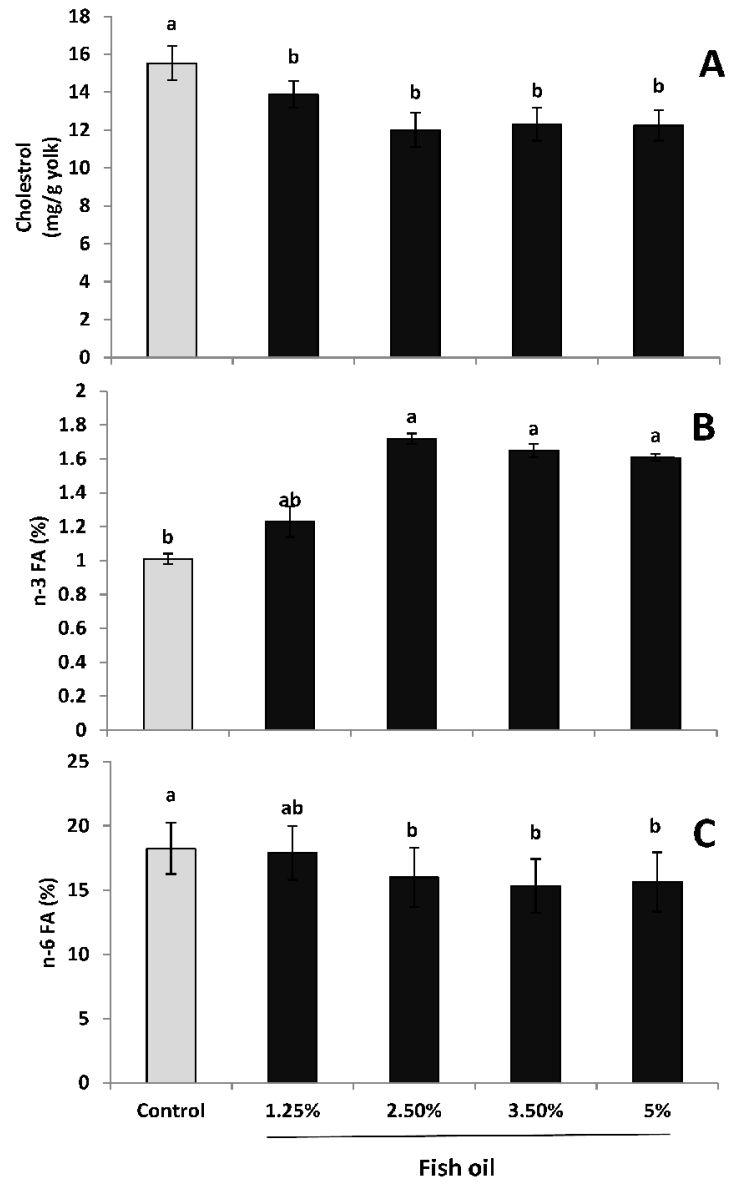

Figure 1. Effect of dietary fish oil on yolk cholesterol (A), omega-3 fatty acids (B) and omega- 6 fatty acids (C). Values are expressed as means \pm standard error.; $\mathrm{a}-\mathrm{c}$ Means with different superscripts differ from each other $(\mathrm{P}<0.05)$.

\section{Discussion}

The present study shows that feeding fish oil improved hen's performance due to increased body weight and decreased feed intake. Similar results were documented by Novak and Scheideler (2001). They indicated that a decrease in feed consumption resulted in an increased in hen weights. Generally, previous studies noted that there was no specific trend of the effect of FO on layers body weight. Kang et al. (2001) stated a significant increase in body weight by using cod liver oil. Contrarily, Ahn et al. (1999) found that when laying hen were fed diets containing $0,2.5$, or $5 \%$ conjugated linoleic acids, body weight gain was adversely affected by feeding 5\% conjugated linoleic acid. On the other hand, Gonzalez and Leeson (2000) proved that when laying hens were fed diets with 2 , 4 , or $6 \%$ menhaden oil; body weight gain from 19 to $55 \mathrm{wk}$ of age was not affected by the dietary treatments.
Also, Mostafa et al. (2013) reported that rat's body weight not affected by feeding different source of oils content omega-3. Deborah et al. (2005) showed that when laying hens were fed diets with 0 (control), 1.25, 2.5, or 5\% seal blubber oil, the body weight of hens was homogeneous. No significant differences were obtained between control diet and $5.0 \%$ FO treatment, meanwhile there was a significant different between control and 1.25, 2.5, and $3.5 \%$ FO treatments. Dietary fish oil has been reported to decrease egg production. This result could be attributed to reduction in feed consumption. Ayerze (1999) reported that the significant differences between treatments in egg production could be due to the somewhat unbalanced test diet, in terms of oil contents. Jones et al. (2000) proved that feed consumption is positively related to egg production; therefore decreasing feed intake will lead to reduce egg production. Similarly, Pal et al. (2004) elucidated that hens fed cod liver oil diets showed the lowest rate of egg production. Also, Shang et al. (2004) observed that when laying hen were fed diets containing $0,1,2,3,4,5$, or $6 \%$ conjugated linoleic acid, egg production was decreased linearly. On the other hand, Basmacoglu et al. (2003) proved that when laying hens were fed different diets containing no fish oil and flaxseed; $1.5 \%$ FO; $4.32 \%$ flaxseed; $1.5 \% \mathrm{FO}+4.32 \%$ flaxseed and $8.64 \%$ flaxseed, egg production of hens fed a diet containing $4.32 \%$ FO was significantly higher than the controls. The type of diet did not affect egg production traits. Cachaldora et al. (2005) indicated that when hens were fed diets with 2 levels of fish oil $(0$ and $17 \mathrm{~g} / \mathrm{kg})$, egg production characteristics were not affected. These data are in agreement with results found by Carrillo et al. (2005) who proved that when laying hens were fed diets with red crab meal (a source of omega-3 fatty acids), egg production was not influenced by dietary treatment.

Egg quality characteristics were affected by feeding fish oil. Shell thickness, shell percentage, yolk height and yolk color were significantly affected by FO supplementation. Heavier and thicker shells were found in eggs laid in $3.5 \% \mathrm{FO}$ group. Shell thickness in 3.5\% FO group was 0.419 $\mathrm{mm}$ while it was $0.389 \mathrm{~mm}$ in control group. Similar results were reported by Shang et al. (2004) who proved that dietary conjugated linoleic acid $(0$, $1,2,3,4,5$, or $6 \%$ ) increased shells weight and improved shell thickness. On the other hand, Pappas et al. (2005) noted that dietary FO reduced shell thickness compared with dietary soybean oil. 
Hammershoj (1995) reported that feeding 3\% fish oil resulted in lower shell quality. Novak and Scheideler (2001) postulated that when flaxseed-fed hens produced eggs with less percentage of wet shell than controls. The present study postulated that darker yolk color was obtained in 5\% FO treatment. Hammershoj and Parkhurst (1995) noted that yolk color also benefited from omega-3, the oxycarotenoids contained in the diet are lipid soluble and therefore, their absorption from the intestine is likely to be improved when fed the lipids. In fact, yolk color is an important quality trait in influencing consumer acceptance. With respect to the effect of fish oil supplementation on yolk color, Jiang et al. (1992) stated that feeding flax seed to laying hens resulted in darker yolks than other dietary groups, darker yolks might be more appealing to consumers of certain ethnic groups. These observations are in coincident with Hammershoj (1995) who proved that when laying hens were fed diets with fish oil and animal fat, darker yolks were observed in fish oil groups. Herber and Van Elswyk (1998) noted that dietary marine micro algal (as a source of omega-3 PUFA) may also be useful in certain geographical regions for enhancing yolk color.

Egg yolk cholesterol was decreased significantly by feeding fish oil. Nestel et al. (1984) observed that reduction of hepatic synthesis as well as increased proximal beta oxidation activity. Kang et al. (2001) noted that reduction in cholesterol by dietary fish oil suggested mainly from the inhibition of hepatic VLDL production. Novak and Scheideler (2001) found that production of an egg with less yolk and a small decrease in yolk solids. The production of an egg with decreased egg yolk may decrease the amount of cholesterol present per egg consumed. The same trends were stated by Vasko et al. (2005). Ouyang et al. (2004) noted that when laying hens were fed with diet supplemented with $5 \%$ fish oil, $5 \%$ palm oil, and 5\% soybean oil, the cholesterol level in yolk of fish oil group was lower than Palm oil and control $(\mathrm{P}<0.01)$. The results demonstrated that fish oil could decrease the cholesterol. Vasko et al.(2005) found that when laying hens were fed three diets supplemented with flax oil and fish oil, concentrations of cholesterol in the egg yolk significantly decreased in the groups with supplementation of flax and fish oil (11.98 and $11.79 \mathrm{mg} / \mathrm{g}$ ). Omega-3 fatty acids were increased while omega- 6 was decreased by feeding fish oil. Several attempts have been made to reverse the decline in human egg consumption by changing egg composition through feeding hens modified diets. Incorporation of n-3PUFA in egg yolks by changing hen diets has been more successful and has been reported in a number of studies (Caston et al., 1994; Scheideler and Froning, 1996). These experiments altered the yolk fatty acid profile by adding either fish products or flax seed to the hens' feed. Similar findings were detected in the present study. Generally, the fatty acid composition of the yolks reflected the dietary fish oil levels. The changes in yolk omega-3 and omega- 6 fatty acids shown here due to feeding graded levels of fish oil are in agreement with previous reports (Van Elswyk et al., 1995; Van Elswyk 1997; Hoffman et al., 2004). They reported that the most significant effect of dietary fish oil was on long chain n-3 PUFA. Moreover, Schreiner et al. (2004) observed that feeding fish oil at $1.25 \%$ led to an increase $(\mathrm{P}<$ 0.0001) in the long-chain n-3 PUFA in the egg yolk lipids. Egg enriched with n-3PUFA may be associated with off-odours and in particular fishy taints. However, these can be minimized if the hens are fed $3.5 \%$ or less of high quality fish oil or $5 \%$ or less flaxseed (Deborah et al., 2005). Van Elswyk et al. (1994) indicated that egg yolk n-3 fatty acids content was significantly increased when hens fed diets enriched with 3\% fish oil. Kang et al. (2001) observed that when hens were fed on a modified diet in which $3 \%$ cotton seed oil was replaced by active EPA-cod liver oil, an increased in Linolenic acid was detected.

\section{In conclusion}

The present study clearly shows that by add $3.5 \%$ of fish oil in laying hens diets, egg cholesterol can be decreased this due to reduction of hepatic synthesis as well as increased proximal beta oxidation activity or due to the inhibition of hepatic VLDL and LDL production. Also, egg quality was improved by increased in shell thickness and yolk color. Furthermore, add 3.5\% fish oil in the diets can change the fatty acids profile in the liver then these fatty acids were enriched in yolk. So in future we can produce a health eggs by feeding fish oil to laying hens and human consuming this type of eggs may have beneficial health effect.

\section{References}

Ahn, D. U., J. L. Sell, C. JO, M. Chamruspollert and M. Jeffrey. 1999. Effect of Dietary Conjugated Linoleic Acid on the Quality Characteristics of Chicken Eggs During Refrigerated Storage. Poultry Sci. 78:922-928.

Ayerza, R. and W. Coates. 1999. An omega-3 fatty acid enriched chia diet: its influence on egg fatty acid composition, cholesterol and oil content. Can. J. Anim. Sci. 79:53-58. 
Basmacoglu, H., M. Cabuk, K. Unal, K. Ozkan, S. Akkan and H. Yalcn. 2003. Effects of dietary fish oil and flax seed on cholesterol and fatty acid composition of egg yolk and blood parameters of laying hens. South Afr. J. Anim. Sci. 33(4):266-273.

Baucell, M. D., N. Crespo, A. C. Barroeta, F. S. Lopez and M. A. Grashorn. 2000. Incorporation of different polyunsaturated fatty acids into eggs. Poultry Sci. 79:51-59.

Brandt, A. E. and W. E. Lands. 1968. Quantitative gas chromatography, using retention times. Lipids 2:178-81.

Cachaldora, P, R. P. Garcia, C. Alvarez, J. Mendez and J. C. Blas. 2005. Effect of conjugated linoleic acid, high-oleic sunflower oil and fish oil dietary supplementation on laying hen egg quality. Spanish J. Agri. Res. 3:74-82.

Carrillo, D. S., J. M. E. Carranco, D. R Castillo, G. M. M. I. Castro, G. E. Avila and G. F. Perez. 2005. Cholesterol and n-3 and n-6 fatty acid content in eggs from laying hens fed with red crab meal (Pleuroncodes planipes). Poultry Sci. 84:167-172.

Caston, L. J., E. J. Squires and S. Leeson. 1994. Hen performance, egg quality and the sensory evaluation of eggs from SCWL hens fed dietary flax. Can. J. Anim. Sci. 74:347-353.

Deborah, P., W. H. Howard, S. Matthias, B. Emanuele and G. F. Natale. 2005. Positional analysis of egg triacylglycerols and phospholipids from hens fed diets enriched with refined seal blubber oil. J. Sci. Food Agric. 85:1703-1714.

Eid, Y. Z. 2005 Hen eggs beyond the nutritional value. Proceedings of the 3rdInternational poultry conference, 4-7 April, Hurghada Egypt.

Gonzalez, E. R. and S. Leeson. 2000. Effect of feeding hens regular or deodorized menhaden oil on production parameters, yolk fatty acid profile, and sensory quality of eggs. Poultry Sci. 79:1597-1602.

Hammershoj, M. 1995. Effects of dietary fish oil with natural content of carotenoids on fatty acid composition, n-3 fatty acid content, yolk color and egg quality of hen eggs. Arch. Geflugelkunde 59:189-197.
Herber, M. S. M. and M. E. Van Elswyk. 1998. Dietary Marine Algae Maintains Egg Consumer Acceptability While Enhancing Yolk Color. Poultry Sci. 77:493-496.

Hoffman, D. R., R. C. Theuer, Y. S. Castaneda, D. H. Wheaton, R. H. Bosworth and A. R. Connor. 2004. Maturation of visual acuity is accelerated in breast-fed term infants fed baby food containing DHA-enriched egg yolk. J. Nutr. 68:881-886.

Jiang, Z., D. U. Ahn, L. Ladner and J. S. Sim. 1992. Influence of feeding full fat flax and sunflower seeds on internal and sensory qualities of eggs. Poultry Sci. 71:378-382.

Jones, S., D. W. L. Ma, F. E. Robinson, C. J. Field and M. T. Clandinin. 2000. Isomers of conjugated linoleic acid (CLA) are incorporated into egg yolk lipids by CLA-fed laying hens. J. Nutr. 130:202-205.

Kang, K. R., G. Cherian and J. S. Sim. 2001. Dietary palm oil alters the lipid stability of polyunsaturated fatty acidmodified poultry products. Poult. Sci. 80:228-234.

Mostafa, R. A., Y. G. Moharram, S. Ramadan, S. Attia and A. El- Sharnouby. 2013. Utilization of some vegetable oil blends rich in omega-3 fatty acids: Biological evaluation. Emir. J. Food Agric. 25(5):320-330.

National Research Council of the National Academies. Air Emissions from Animal Feeding Operations: Current Knowledge, Future Needs. Board on Agriculture and Natural Resources, Board on Env. Studies and Toxicol. The National Academies Press, Washington, D.C. 2003.

Nestel, P. L., W. E. Cannor, M. F. Reardon, S. Cannor, S. Wong and R. Boston. 1984. Supperssion by diets rich in fish oil of very low density lipoprotein production in man. J. Clin. Invest.74:82-89.

Novak, C. and S. E. Scheideler. 2001. Long-term effects of feeding flaxseed-based diets. Egg production parameters, components, and eggshell quality in two strains of laying hens. Poultry Sci. 80:1480-1489.

Ouyang, K., W. J. Wang, M. S. Xu, J. Yan and S. G. Xinchen. 2004. Effects of different oils on the production performances and polyunsaturated fatty acids and cholesterol 
levels of yolk in hens. Asian Austr. J. Anim. Sci. 17:843-847.

Pal, L., R. Grossmann, K. Dublecz, F. Husveth, L. Wagner, A. Bartos and G. Kovacs. 2004. Effects of glucagon and insulin on plasma glucose, triglyceride, and triglyceride-rich lipoprotein concentrations in laying hens fed diets containing different types of fats. Poultry Sci. 81:1694-1702.

Pappas, A. C., T. Acamovic, N. H. C. Sparks, P. F. Surai and R. M. Devitt. 2005. Effects of supplementing broiler breeder diets with organic selenium and polyunsaturated fatty acids on egg quality during storage. Poultry Sci. 84:865-874.

Radwan, S. S. 1978. Coupling of two dimensional thin layer chromatography with gas chromatography of the quantitative analysis of lipids classed and their constituent fatty acids. J. Chromatog. Sci.16:538-542.

Richmond, W. 1973. Preparation and properties of a cholesterol oxidase from Nocardia sp. and its application to the enzymatic assay of total cholesterol in serum. Clin. Chem. 19:13501356.

Scheideler, S. E. and G. W. Froning. 1996. The combined influence of dietary flaxseed variety, level, form and storage conditions on egg production and composition among vitamin esupplemented hens. Poultry Sci. 75:12211226.

Schreiner, M., H. W. Hulan, F. E. Razzazi Bohm and C. Iben. 2004. Feeding laying hens seal blubber oil: Effects on egg yolk incorporation, stereospecific distribution of omega-3 fatty acids, and sensory aspects. Poultry Sci. 83:462-473.

Shang, X. G., F. L. Wang, D. F. Li, J. D. Yin and J. Y. Li. 2004. Effects of dietary conjugated linoleic acid on the productivity of laying hens and egg quality during refrigerated storage. Poultry Sci. 83:1688-1695.

Simopoulos, A. P. 2000. Human requirement for n3 polyunsaturated fatty acids. Symposium: Role of poultry products in enriching the human diet with n- 3 PUFA. Poultry Sci. 79:961-970.

Statistical Packages for the Social Sciences. Statistical software for windows version 17.0 Microsoft, SPSS, Chicago, IL, USA. 2008.

Van Elswyk, M. E. 1997. Comparison of n-3 fatty acid sources in laying hen rations for improvement of whole egg nutritional quality: A review. Br. J. Nutr. 78:S61-S69.

Van Elswyk, M. E., P. L. Dawson and A. R. Sams. 1995. Dietary menhaden oil influences sensory characteristics and head space volatiles of shell eggs. J. Food Sci. 60:85-89.

Van Elswyk, M. E., B. M. Hargis, J. D. Williams and P. S. Hargis. 1994. Dietary menhaden oil contributes to hepatic lipidosis in laying hens. Poultry Sci. 73:653-662.

Vasko, L., M. Tukova and R. Kastel. 2005. Metabolic parameters of laying hens and production of eggs after supplementation of food rations with a higher content of PUFA from flax and fish oil. Slovensky Veterinarsky asopis 30:38-40. 